\title{
Tripeptide Self-Assembly into Bioactive Hydrogels: Effects of Terminus Modification on Biocatalysis
}

\author{
Marina Kurbasic, Ana M. Garcia, Simone Viada and Silvia Marchesan *(D) \\ Chemical \& Pharmaceutical Sciences Department, University of Trieste, 34127 Trieste, Italy; \\ marina.kurbasic@studenti.units.it (M.K.); anamariagarcia.1988@gmail.com (A.M.G.); \\ simone.viada@studenti.units.it (S.V.) \\ * Correspondence: smarchesan@units.it; Tel.: +39-040-5583923
}

Citation: Kurbasic, M.; Garcia, A.M.; Viada, S.; Marchesan, S. Tripeptide Self-Assembly into Bioactive Hydrogels: Effects of Terminus Modification on Biocatalysis. Molecules 2021, 26, 173. https:/ /doi. org $/ 10.3390 /$ molecules 26010173

Academic Editor: Derek J. McPhee Received: 9 December 2020 Accepted: 28 December 2020 Published: 31 December 2020

Publisher's Note: MDPI stays neutral with regard to jurisdictional clai$\mathrm{ms}$ in published maps and institutional affiliations.

Copyright: (C) 2020 by the authors. Licensee MDPI, Basel, Switzerland. This article is an open access article distributed under the terms and conditions of the Creative Commons Attribution (CC BY) license (https:// creativecommons.org/licenses/by/ $4.0 /)$.

\begin{abstract}
Bioactive hydrogels based on the self-assembly of tripeptides have attracted great interest in recent years. In particular, the search is active for sequences that are able to mimic enzymes when they are self-organized in a nanostructured hydrogel, so as to provide a smart catalytic (bio)material whose activity can be switched on/off with assembly/disassembly. Within the diverse enzymes that have been targeted for mimicry, hydrolases find wide application in biomaterials, ranging from their use to convert prodrugs into active compounds to their ability to work in reverse and catalyze a plethora of reactions. We recently reported the minimalistic L-His-D-Phe-D-Phe for its ability to self-organize into thermoreversible and biocatalytic hydrogels for esterase mimicry. In this work, we analyze the effects of terminus modifications that mimic the inclusion of the tripeptide in a longer sequence. Therefore, three analogues, i.e., $N$-acetylated, $C$-amidated, or both, were synthesized, purified, characterized by several techniques, and probed for self-assembly, hydrogelation, and esterase-like biocatalysis. This work provides useful insights into how chemical modifications at the termini affect self-assembly into biocatalytic hydrogels, and these data may become useful for the future design of supramolecular catalysts for enhanced performance.
\end{abstract}

Keywords: peptides; hydrogels; biomaterials; self-assembly; chirality; D-amino acids; hydrolase; biocatalysis

\section{Introduction}

The ability of natural enzymes to catalyze reactions with exquisite selectivity in water has been inspiring scientists for a long time in the search for simpler, synthetic mimetics that are ultimately biodegradable for a low impact on the environment [1]. In the area of biomaterials, enzyme mimicry has found a wide variety of applications to tackle unsolved challenges, ranging from combating biofilms [2] to cancer therapy [3]. In particular, hydrolases are among the most studied targets to develop mimetics thanks to their robustness and ability to catalyze a wide range of reactions [4,5]. They have been anchored on biopolymers for enhanced activity and durability [6], or they have been used for the formation of products for biomedical use [7]. A popular strategy includes hydrolasesensitive bioactive molecules in the biomaterial to make it adaptive to the biological milieu, for tissue engineering [8], immunomodulation [9], or antimicrobial activity [10], for instance.

One shortcoming of enzymes, however, is that they typically comprise over one hundred amino acids and may even trigger an immune response; thus, it is not surprising that the search has been very active to replace them with shorter sequences [11]. Selfassembling peptides appear ideal candidates thanks to the possibility to encode catalytic functions of the enzyme directly into the peptide sequence, combined with the ability to form supramolecular hydrophobic pockets for reactions to occur, as well as the added value of multivalency of the resulting (nano)structures [12]. However, their design is notoriously challenging, especially in light of the diverse conformations they can adopt [13]. 
Nevertheless, different strategies proved successful [14], also aimed at the formation of catalytic hydrogels as functional materials [15].

A very popular approach to achieve a biocatalytic nanostructure for hydrolase mimicry consists of the design of a self-assembling peptide that contains histidine (His) in the sequence. Earlier reports demonstrated that this strategy was successful on several 14-mers [16]. Since then, there has been a continuous effort toward the inclusion of His in smallmolecular-weight derivatives as gelators [17] or the gradual shortening of the peptide sequence, for instance to 13-mers [18], 11-mers [19], heptapeptides [20,21], tetrapeptides [22], tripeptides [23,24], or cyclic dipeptides [25]. In other systems, activity could be boosted by the presence of cations, such as zinc [26-29] or iron [30], or by additional amino acids to mimic the catalytic triad (Scheme 1) [31], such as Ser, [32,33] Arg [16,34], or Asp [35,36]. We recently reported a minimalistic sequence composed of the unprotected, heterochiral tripeptide L-His-D-Phe-D-Phe (or its enantiomer D-His-L-Phe-L-Phe), able to self-organize in phosphate buffer into biocatalytic nanostructures that, at higher concentrations, yielded thermoreversible hydrogels [24]. The design was based on the combination of both D- and L-amino acids at specific positions along a heterochiral sequence [37], so that gelling, amphipathic supramolecular structures could arise due to the diphenylalanine self-assembling motif [38]. When assembled, the tripeptide demonstrated an esterase-like activity on the hydrolysis of 4-nitrophenyl acetate (pNPA), a model compound that got hydrolyzed to the yellow-colored 4-nitrophenol ( $\mathrm{pNP}$ ) [39]. A proposed mechanism involves the presence of both a free base acting as a nucleophile or general base (e.g., the His side chains or amine at the $\mathrm{N}$-terminus), as well as a protonated His stabilizing the oxyanion intermediate [40]. Self-assembly leads to a change in the chemical environment around the His residues, and this is a well-known factor [41-43] that can induce an apparent pKa shift [44] which could activate the peptide, thus mimicking the role played for instance by Asp in the catalytic triad [41]. An attractive feature of supramolecular peptide-based catalysts is the possibility to recycle the systems, for instance, by means of $\mathrm{pH}$ switches to control assembly/disassembly cycles [45].

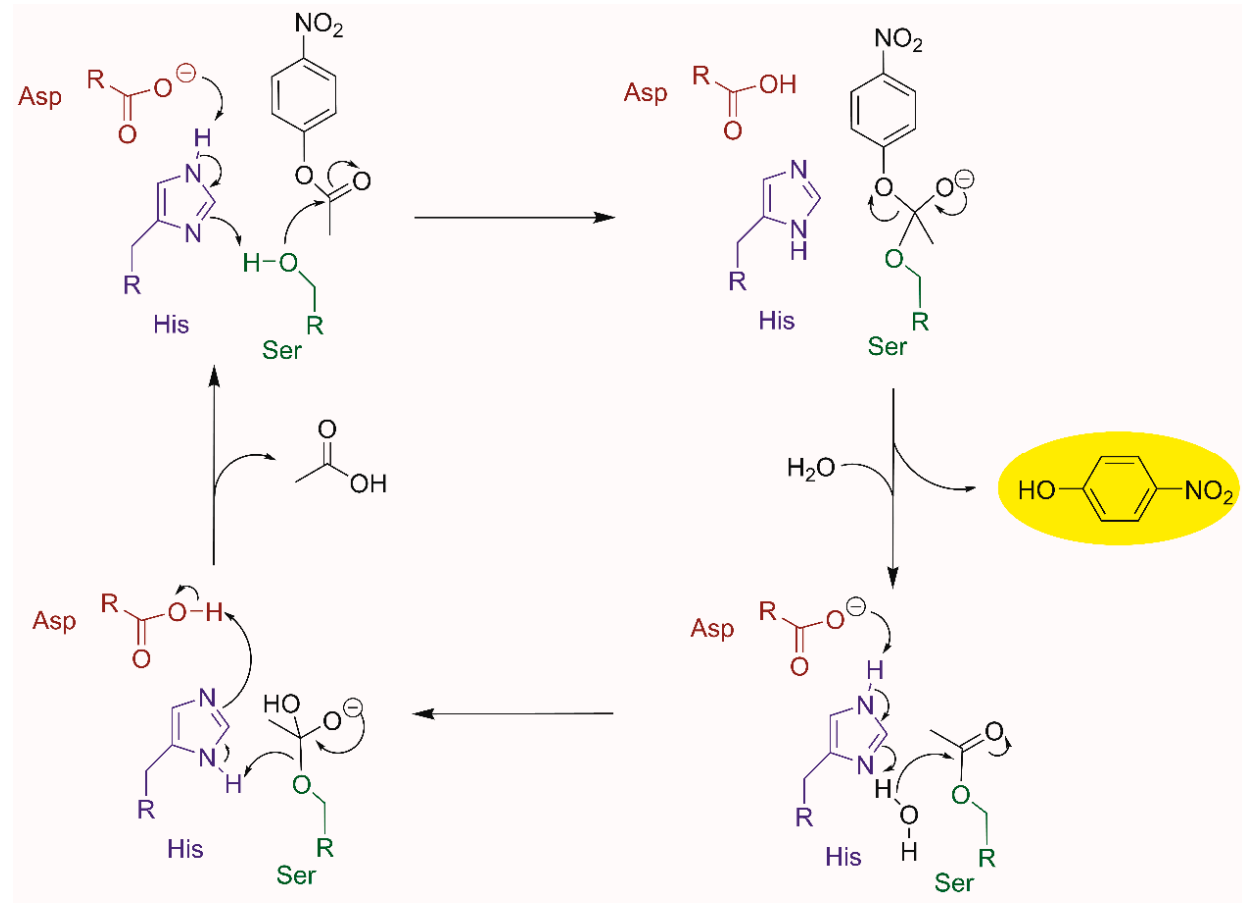

Scheme 1. Example of catalytic mechanism of serine proteases for the hydrolysis of 4-nitrophenyl acetate, a common substrate, that leads to the formation of the yellow-colored 4-nitrophenol that can be measured spectrophotometrically. 
Nevertheless, the de novo design of catalytic supramolecular systems based on minimalistic peptides is still rather challenging, and even minor structural modifications may affect self-assembly and catalysis in ways that are difficult to predict. For instance, Cterminal amidation was previously reported to accelerate the gelation kinetics of Fmoc-Phe derivatives [46], whereas presence of a carboxylic acid moiety at the C-terminus may assist with the catalysis [33]. Therefore, in order to gain new insights into these systems, this work analyzed the supramolecular behavior and catalytic performance of D-His-L-Phe-L-Phe $\mathrm{N}$-acetylated, $\mathrm{C}$-amidated, or both, with the ultimate aim of gathering useful information for the future design of enhanced systems.

\section{Results and Discussion}

\subsection{Peptide Self-Assembly into Nanostructured Hydrogels}

The peptides shown in Scheme 2 were synthesized in solid phase according to established protocols [47], purified by reverse-phase HPLC, freeze-dried, and characterized by ${ }^{1} \mathrm{H}$ - and ${ }^{13} \mathrm{C}-\mathrm{NMR}$ and ESI-MS to verify their purity and identity (see Supplementary Materials). At neutral $\mathrm{pH}$, the parent compound L-His-D-Phe-D-Phe (or its enantiomer DHis-L-Phe-L-Phe) was shown to stack, through hydrogen bonding between amide groups, into $\beta$-sheet-like structures to give rise to amyloid fibrils, which, at higher concentrations, further bundled into fibers and gelled [24]. Analogously, each peptide 1-3 was tested for self-assembly and hydrogelation in phosphate buffer at neutral $\mathrm{pH}$. Interestingly, $\mathrm{N}$ acetylated $\mathbf{1}$ did not gel at all, yielding macroscopic aggregates beyond its solubility limit. By contrast, 2 and 3 formed stable hydrogels already at $25 \mathrm{mM}$ (Table 1 and Figure 1). For comparison, the tripeptide analogue with unprotected termini displayed a minimum gelling concentration $(\mathrm{mgc})$ of $50 \mathrm{mM}$ [24]. We inferred that terminus modification increased the compound hydrophobicity and lowered the mgc. HPLC retention times (see Supplementary Materials), which can be considered an experimental measure of hydrophobicity [48], were in the order $\mathbf{2}<<\mathbf{3} \approx \mathbf{1}$, which can be rationalized considering that $\mathbf{2}$ is the only one with an ionizable group at the N-terminus. Additionally, hydrogelation is a complex process that requires not only hydrophobicity to drive molecular aggregation, but also the generation of amphipathic architectures, whereby hydrophilic surfaces engage through hydrogen-bonding interactions with water [48]. If compound 1 displayed a deprotonated carboxylate anion at the $\mathrm{C}$-terminus at neutral $\mathrm{pH}$, then it would have fewer hydrogen-bonding donors relative to amidated 2 and 3 and, thus, reduced possibilities for interactions with water, which may explain the formation of aggregates as opposed to a hydrogel.<smiles>[R]N[C@@H](Cc1c[nH]cn1)C(=O)N[C@@H](Cc1ccccc1)C(=O)N[C@H](Cc1ccccc1)C([R])=O</smiles>

$1 \mathrm{R}=\mathrm{COCH}_{3} \quad \mathrm{R}^{\prime}=\mathrm{OH}$

$2 \mathrm{R}=\mathrm{H} \quad \mathrm{R}^{\prime}=\mathrm{NH}_{2}$

$3 \mathrm{R}=\mathrm{COCH}_{3} \quad \mathrm{R}^{\prime}=\mathrm{NH}_{2}$

Scheme 2. The three tripeptides studied in this work. 
Table 1. Hydrogels were formed by compounds 2 and 3, but not 1, in phosphate buffer at neutral $\mathrm{pH}$.

\begin{tabular}{cccccc}
\hline Tripeptide & N-Terminus & C-Terminus & $\mathbf{1 ~} \mathbf{~ M}$ & $\mathbf{2 5} \mathbf{~ m M}$ & $\mathbf{5 0 ~} \mathbf{m M}$ \\
\hline L-His-D-Phe- & $\mathrm{NH}_{2}$ & $\mathrm{COOH}$ & Sol & Sol & Hydrogel \\
D-Phe & Acetylated & $\mathrm{COOH}$ & Sol & Sol & Aggregates \\
$\mathbf{1}$ & $\mathrm{NH}_{2}$ & Amidated & Sol & Hydrogel & Hydrogel \\
$\mathbf{2}$ & Acetylated & Amidated & Sol & Hydrogel & Hydrogel \\
$\mathbf{3}$ & & & &
\end{tabular}

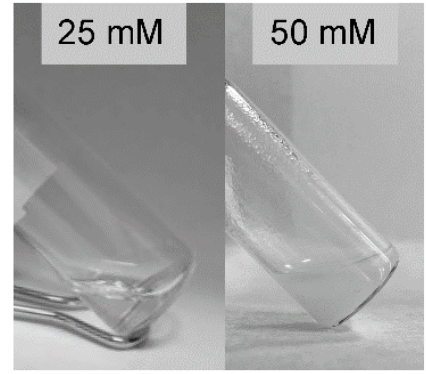

(a)

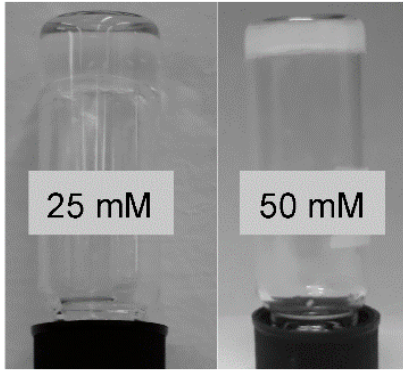

(b)

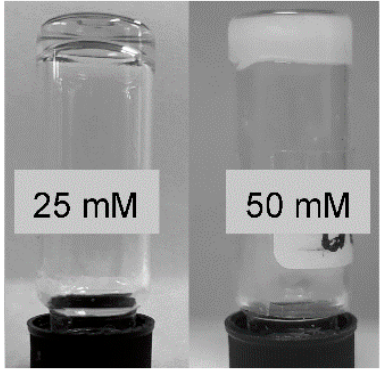

(c)

Figure 1. Photographs of (a) 1, (b) 2, and (c) 3 in phosphate buffer at 25 and $50 \mathrm{mM}$.

Transmission electron microscopy revealed the presence of nanofibrils in all cases (Figure 2). Interestingly, their diameters were $11 \pm 1 \mathrm{~nm}$ for $\mathbf{1}, 8 \pm 2 \mathrm{~nm}$ for 2, and $11 \pm 3 \mathrm{~nm}$ for $3(n=100)$. Oscillatory rheometry was then used to assess the viscoelastic properties of the resulting materials (Figure 3). Both 2 and 3 gelled within a minute, with gelation kinetics being faster for 2 relative to 3 . A possible explanation lies in the fact that only 2 displays an ionizable N-terminus; thus, following the $\mathrm{pH}$ trigger, the ammonium species forms immediately and prompts gelation. By contrast, the ionization state of $\mathbf{3}$ is not expected to vary upon application of the $\mathrm{pH}$ change from alkaline to neutral, and it may, thus, take longer for this species to self-organize into a fibrillar hydrogel. After $1 \mathrm{~h}$, the elastic modulus $G^{\prime}$ reached $23 \mathrm{kPa}$ for 2 and $68 \mathrm{kPa}$ for 3 . The higher stiffness for the hydrogel composed of $\mathbf{3}$, relative to $\mathbf{2}$, was in agreement with the wider fibrils observed by TEM for the former relative to the latter. Stress sweeps revealed a linear viscoelastic region up to ca. $70 \mathrm{~Pa}$ for 2 and $30 \mathrm{~Pa}$ for 3 . It is possible that the thinner fibrils of 2 displayed higher interconnectivity leading to higher stability against applied stress, as already observed for other gelling heterochiral tripeptides [48].

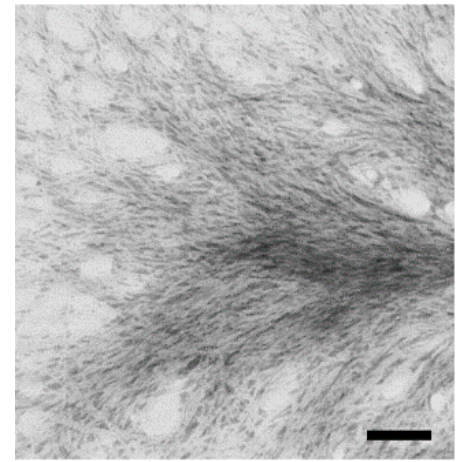

(a)

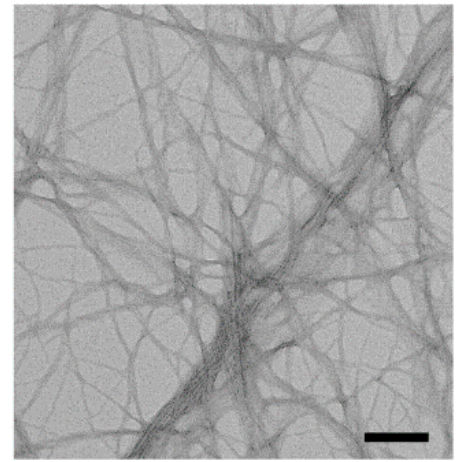

(b)

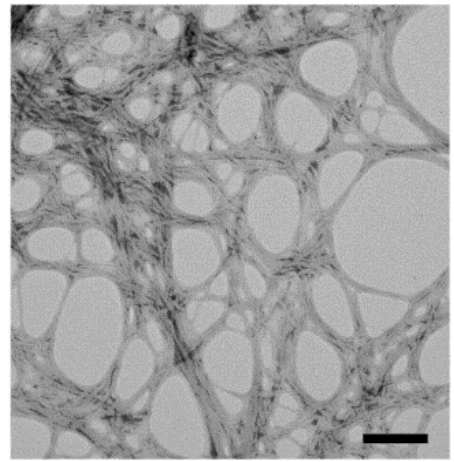

(c)

Figure 2. TEM micrographs of (a) 1, (b) 2, and (c) 3 nanofibrils (25 mM). Scalebar $=200 \mathrm{~nm}$. 


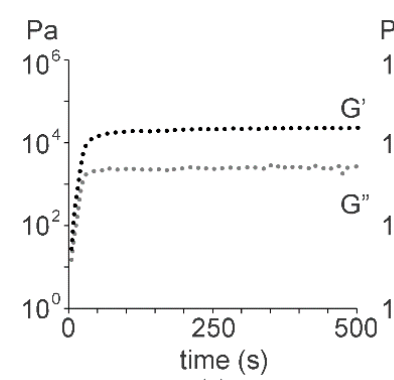

(a)

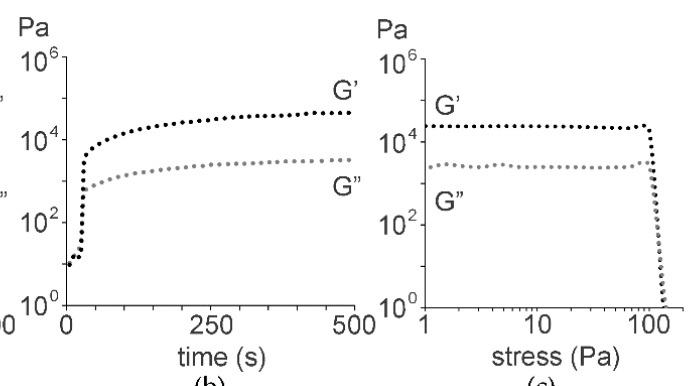

(b)

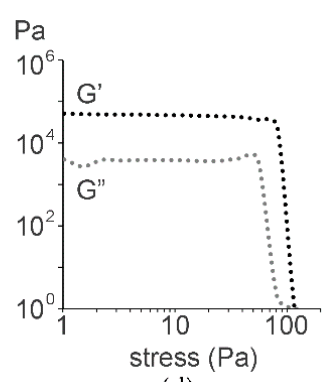

(d)

Figure 3. Oscillatory rheometry time sweeps for (a) 2 and (b) 3; stress sweeps for (c) 2 and (d) 3.

\subsection{Peptide Conformational Study}

Circular dichroism (CD) spectra were acquired in the sol state $(1 \mathrm{mM})$ for each compound (Figure 4a). $\mathbf{1}$ and $\mathbf{2}$ displayed very weak signals; however, the overall signature with two maxima at 199 and $219 \mathrm{~nm}$ was analogous to the one previously observed for similar assembling heterochiral tripeptides [48]. In that case, a combination of experimental and in silico data allowed deciphering the CD spectra as a population of conformations in solution, of which the most stable populated the top-left quadrant of the Ramachandran plot, where $\beta$-structures (sheets and turns) are located. By contrast, the spectrum of 3 was dissimilar and displayed a negative signal under $200 \mathrm{~nm}$, and a positive maximum centered at $223 \mathrm{~nm}$, with visible scattering occurring at higher wavelengths. This signal was already reported for similar short peptides that displayed Phe-Phe interactions and may be indicative of compound 3's marked tendency to stack into fibrils that yield scattering [49]. $\mathrm{CD}$ data were also acquired at gelling concentrations (Figure $4 \mathrm{~b}$ ), although, in this case, acquisition was possible only above $220 \mathrm{~nm}$ due to high voltage. Interestingly, assembly significantly altered the spectra for both 2 and 3 since the gels displayed a negative minimum at 230 and $238 \mathrm{~nm}$, respectively. Furthermore, the gel of 3 displayed the typical vibronic signature for the forbidden $\pi-\pi^{*}$ transition of the aromatic side chains of Phe, as a result of its inclusion in a supramolecular chiral environment, noted also for the parent compound [24].

Thioflavin T fluorescence (ThT) was then used as an assay to determine the presence of amyloid structures [50], since the dye is known to bind onto hydrophobic grooves of the surface of fibrils composed of at least four consecutive $\beta$-sheets [51]. As a result of the binding, the rotation is impeded between the two aromatic rings that compose the dye, yielding fluorescence [52]. Surprisingly, only compound 3 displayed marked fluorescence (Figure 4c), despite the fact that all three formed nanofibrils as evidenced by TEM. Clearly, the surface topography of the fibrils composed of 3 was different relative to the other analogues, and it bound thioflavin more efficiently. It has been shown that ThT binding is not mediated by electrostatic interactions, and it is, thus, favored on fibrils formed by neutral species as is compound 3, and disfavored onto highly charged surfaces, as may be those of compounds $\mathbf{1}$ and $\mathbf{2}$ [53]. The amide I region of attenuated total reflectance (ATR) Fourier-transformed infrared (FT-IR) spectra of the three gels (Figure $4 \mathrm{~d}-\mathrm{f}$ ) revealed a major peak at $1638 \mathrm{~cm}^{-1}$ for $\mathbf{1}$ and $\mathbf{3}$, which is typical for $\beta$-sheet-like structures; this signal was shifted to $1645 \mathrm{~cm}^{-1}$ in the case of compound 2 . Compound 3 was the only one to also display an intense signal at $1620 \mathrm{~cm}^{-1}$, which is in the region of amyloid structures, in agreement with the ThT fluorescence data. Additionally, all spectra presented a broad signal in the region of $1670-1680 \mathrm{~cm}^{-1}$ that could be ascribed to the presence of residual trifluoroacetate. 


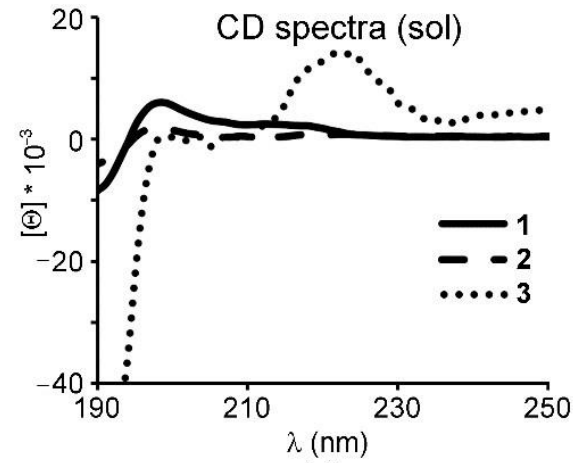

(a)

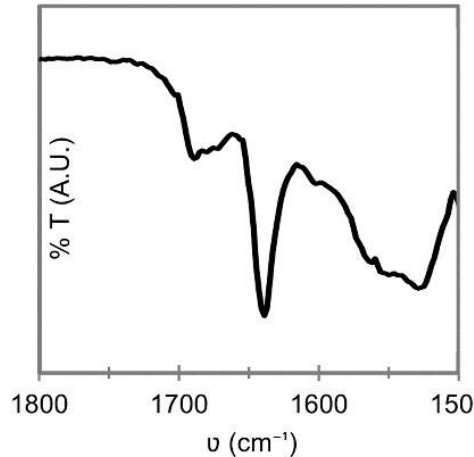

(d)

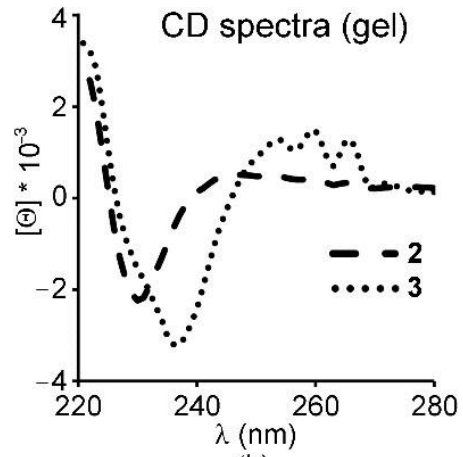

(b)

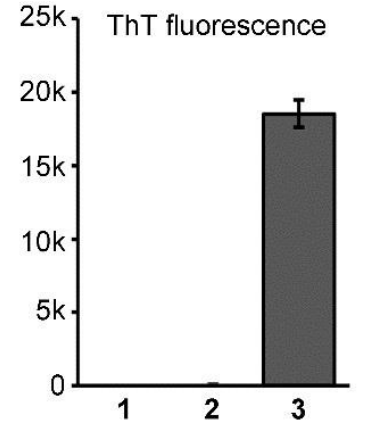

(c)

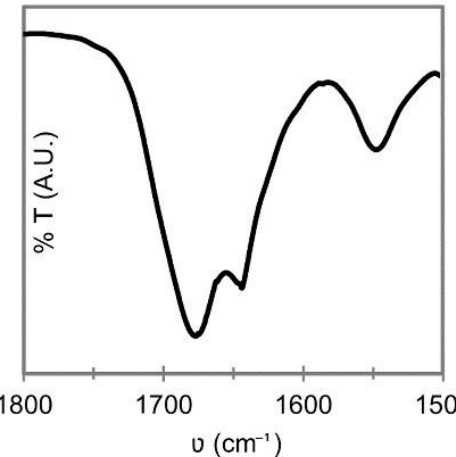

(e)

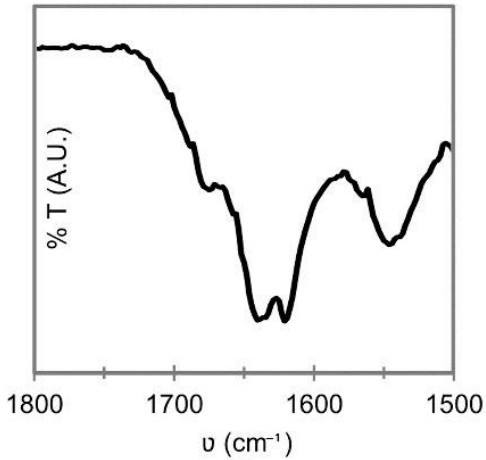

(f)

Figure 4. Circular dichroism (CD) spectra in the sol (a) and gel (b) states; (c) thioflavin T fluorescence; (d-f) Fourier-transform infrared (FT-IR) spectra of compounds $\mathbf{1}(\mathbf{d}), 2(\mathbf{e})$, and $\mathbf{3}(\mathbf{f})$ in the gel state.

Interestingly, when the hydrogels formed by 2 or 3 were tested against heating in a water bath, both started to disassemble at rather high temperature values (i.e., $65^{\circ} \mathrm{C}$ for 2 and $70^{\circ} \mathrm{C}$ for 3 ), but only 2 was thermoreversible and reformed upon cooling to room temperature. By contrast, 3 expelled water and irreversibly formed aggregates.

\subsection{Esterase-Like Biocatalysis}

Having confirmed that all three compounds self-assembled at neutral $\mathrm{pH}$ into fibrils, they were tested as biocatalysts for esterase mimicry. 4-Nitrophenyl acetate (pNPA) was chosen as a model compound, since it gets hydrolyzed to the yellow-colored 4-nitrophenol that can easily be monitored spectrophotometrically [39]. The three compounds in solution at $1 \mathrm{mM}$ did not show significant catalysis, analogously to the parent heterochiral compound His-Phe-Phe [24]. The observed reaction rates with $1 \mathrm{mM}$ pNPA corresponded to $4.43 \times 10^{-5} \mathrm{~s}^{-1}(\mathbf{1}), 2.00 \times 10^{-5} \mathrm{~s}^{-1}$ (2), and $3.85 \times 10^{-5} \mathrm{~s}^{-1}$ (3). Under self-assembly conditions, the thermoreversible hydrogel formed by $\mathrm{C}$-amidated 2 displayed the best catalytic performance, corresponding to a $\mathrm{k}_{\mathrm{obs}}$ of $8.68 \times 10^{-3} \mathrm{~s}^{-1}$ at $50 \mathrm{mM}$, which surpassed that of the parent heterochiral His-Phe-Phe with free termini under analogous conditions $\left(1.7 \times 10^{-3} \mathrm{~s}^{-1}\right)$ [24], thus suggesting that a free carboxylic acid at the C-terminus did not significantly assist in catalysis. In the same conditions, compound $\mathbf{1}$ formed aggregates, whose performance was worse than the fibrils obtained at the lower concentration of $25 \mathrm{mM}$ (Table 2). Compared to the parent compound, the catalytic performance under analogous conditions in the fibril state was slightly worse, suggesting a positive role of the free N-terminus in catalysis. Lastly, compound 3 displayed the worst biocatalytic activity of the set of three. For comparison, under analogous conditions relative to those for the best catalytic performance of $\mathbf{1}$ (bold in Table 1), 3 displayed a $\mathrm{k}_{\mathrm{obs}}$ of $4.55 \times 10^{-4} \mathrm{~s}^{-1}$. It should be noted that it was not possible to analyze the catalytic performance of this compound at $50 \mathrm{mM}$ due to a high level of scattering from the white gel. Overall, the data indicated that $\mathrm{N}$-acetylation negatively affected biocatalysis, while $\mathrm{C}$-amidation alone improved it. 
Table 2. Catalytic rates $\left(\mathrm{k}_{\mathrm{obs}}, \mathrm{s}^{-1}\right)$ of peptides 1-3 on the hydrolysis of 4-nitrophenyl acetate (pNPA). The best performance for each peptide is indicated in bold.

\begin{tabular}{|c|c|c|c|c|c|}
\hline $\begin{array}{c}\text { [pNPA] } \\
\mathrm{mM}\end{array}$ & $\begin{array}{c}1 \\
\text { (Sol) }\end{array}$ & $\begin{array}{c}1 \\
\text { (Fibrils) }\end{array}$ & $\begin{array}{c}1 \\
\text { (Aggregates) }\end{array}$ & $\begin{array}{c}2 \\
\text { (Hydrogel) }\end{array}$ & $\begin{array}{c}3 \\
\text { (Hydrogel) }\end{array}$ \\
\hline 0.2 & $1.02 \times 10^{-5}$ & $2.17 \times 10^{-4}$ & $1.05 \times 10^{-4}$ & $3.55 \times 10^{-4}$ & $3.83 \times 10^{-5}$ \\
\hline 0.4 & $1.65 \times 10^{-5}$ & $4.39 \times 10^{-4}$ & $2.00 \times 10^{-4}$ & $2.60 \times 10^{-3}$ & $1.50 \times 10^{-4}$ \\
\hline 0.6 & $2.43 \times 10^{-5}$ & $7.61 \times 10^{-4}$ & $3.57 \times 10^{-4}$ & $5.00 \times 10^{-3}$ & $3.11 \times 10^{-4}$ \\
\hline 0.8 & $3.02 \times 10^{-5}$ & $9.70 \times 10^{-4}$ & $4.32 \times 10^{-4}$ & $7.26 \times 10^{-3}$ & $4.41 \times 10^{-4}$ \\
\hline 1.0 & $4.43 \times 10^{-5}$ & $1.16 \times 10^{-3}$ & $6.60 \times 10^{-4}$ & $8.68 \times 10^{-3}$ & $4.55 \times 10^{-4}$ \\
\hline
\end{tabular}

In conclusion, $\mathrm{N}$-acetylation and/or $\mathrm{C}$-amidation were shown to affect the selfassembly ability and, to a minor extent, the biocatalytic performance of the heterochiral His-Phe-Phe tripeptide [24]. All three compounds self-organized into nanofibrils, although the $\mathrm{N}$-acetylated analogue $\mathbf{1}$ did not gel at all, and the $\mathrm{N}$-acetylated and $\mathrm{C}$-amidated 3 formed irreversible hydrogels. We infer that the presence of fewer hydrogen-bonding donor groups in 1 relative to the other compounds negatively affected its ability to interact with water to gel. Furthermore, compounds 2 and 3 displayed an mgc corresponding to $25 \mathrm{mM}$, in contrast with $50 \mathrm{mM}$ for the parent compound, suggesting that terminal modification increased hydrophobicity and favored hydrogelation. In particular, $\mathrm{C}$-amidated $\mathbf{2}$ was the only compound of the set to maintain the ability to form thermoreversible hydrogels, with an improvement in catalytic performance. These data confirmed that the presence of a free carboxylic acid at the $C$-terminus did not significantly assist in the catalysis performed by this tripeptide sequence. As an additional value, recent reports described a positive effect of $C$-amidation on the stability and biological performance of short heterochiral peptides [36]. Future studies will focus on other strategies to enhance the catalytic activity of the His-Phe-Phe sequence, for instance, through co-assembly with other peptides bearing different amino acids, such as Ser or Arg, which could mimic the catalytic triad found in hydrolases, or through peptide sequence extension to include the same residues. For instance, addition of Arg units at the termini of short self-assembling peptides was shown to reduce hierarchical association of fibrils and improve gelation kinetics [37].

\section{Materials and Methods}

\subsection{Materials and General Methods}

All chemicals and solvents were purchased of analytical grade from Merck (Milan, Italy), except for the reagents used for peptide synthesis, which were purchased from GL Biochem (Shanghai, China). Peptides were synthesized in solid phase using standard protocols based on Fmoc-protection and HBTU/HOAt activation [47]. Purification was performed on reverse-phase HPLC using an Agilent 1260 Infinity system, equipped with a C-18 column (Kinetex, 5 microns, $100 \AA$, $250 \times 10 \mathrm{~mm}$, Phenomenex). The gradient used consisted of acetonitrile/water with $0.05 \%$ TFA with the following program: $\mathrm{t}=0-2 \mathrm{~min}$, $25 \% \mathrm{MeCN} ; \mathrm{t}=14-16 \mathrm{~min}, 95 \% \mathrm{MeCN}$. The purified fractions were freeze-dried to yield a white, fluffy powder. ESI-MS characterization was performed on an Agilent 6120 Infinity (Agilent Technologies, Milan, Italy), and NMR spectra were acquired on a Varian Inova (Varina Inc., Milan, Italy (further details are in the Supplementary Materials). MilliQ water was obtained with an inline Millipore RiOs/Origin system (Merck, Milan, Italy) with resistivity higher than $18 \mathrm{M} \Omega \cdot \mathrm{cm}$. All experiments were performed with each peptide at various concentrations in sodium phosphate buffer $0.1 \mathrm{M}$ with a final $\mathrm{pH}$ of $7.1 \pm 0.1$ following the protocol. Self-assembly was tested by dissolving each compound in $0.1 \mathrm{M}$ sodium phosphate ( $\mathrm{pH} 11.8$ ), followed by mild heating if needed to aid with dissolution to achieve a final $\mathrm{pH}$ of $7.1 \pm 0.1$. Compound 3 could not be dissolved following this protocol at $50 \mathrm{mM}$; therefore, only in this case, the peptide was dissolved in half of the final volume using $0.1 \mathrm{M}$ sodium phosphate buffer at $\mathrm{pH} 5.8$, followed by dilution with an equal volume of $0.1 \mathrm{M}$ sodium phosphate buffer at $\mathrm{pH} 11.8$ to reach the final $\mathrm{pH}$ of $7.1 \pm 0.1$. In the case of peptide solutions at $1 \mathrm{mM}$, each peptide was dissolved in half of the final 
volume consisting of $0.1 \mathrm{M}$ sodium phosphate buffer at $\mathrm{pH} 11.8$, followed by dilution with an equal volume of sodium phosphate $0.1 \mathrm{M}$ at $\mathrm{pH} 5.8$ to reach neutrality as described above. Thermoreversibility was assessed by immersing the vials shown in Figure 1 in an oil bath that was heated at $5{ }^{\circ} \mathrm{C} / \mathrm{min}$ until ca. $80^{\circ} \mathrm{C}$, in which condition no gel residue was left, and samples were left to cool down to room temperature.

\subsection{Oscillatory Rheology}

Hydrogels composed of $\mathbf{2}$ or $\mathbf{3}$ were formed at $25 \mathrm{mM}$ in situ in an oscillatory rheometer Kinexus Ultra Plus (Malvern, Alfatest, Milan, Italy) using a stainless-steel $20 \mathrm{~mm}$ parallel plate geometry at $25^{\circ} \mathrm{C}$. Time sweeps were recorded at a frequency of $1 \mathrm{~Hz}$ and a stress of $5 \mathrm{~Pa}$. Stress sweeps were recorded at $1 \mathrm{~Hz}$. Measurements were repeated twice on independent experiments and a representative dataset is shown.

\subsection{Transmission Electron Microscopy}

TEM micrographs were acquired using a Philips electron microscope 208 (FEI, Hillsboro, Oregon, OR, USA) that was equipped with a Quemesa (Olympus Soft Imaging Solutions (Berlin, Germany) camera; images were recorded with RADIUS software; samples were prepared as described previously using phosphotungstate as a negative stain [24].

\subsection{Circular Dichroism (CD)}

CD spectra were recorded in a J-815 system (Jasco, Easton, MD, USA) using a $0.1 \mathrm{~mm}$ quartz cuvette at $25^{\circ} \mathrm{C}$, with a bandwidth of $1 \mathrm{~nm}$ and a step size of $1 \mathrm{~nm}$ with $1 \mathrm{~s}$ integration. Spectra shown are the average of at least five measurements (one accumulation each).

\subsection{Thioflavin T Fluorescence}

Samples $(0.12 \mathrm{~mL})$ were prepared as described above at $25 \mathrm{mM}$ peptide concentration and immediately put on wells of Greiner 96 Flat Clear-Bottom Black Polystyrene. After $4 \mathrm{~h}$, $30 \mu \mathrm{L}$ of a Thioflavin T solution $(22.2 \mu \mathrm{M}$ in $20 \mathrm{mM}$ glycine- $\mathrm{NaOH}$ pH 8.5, $0.2 \mu \mathrm{m}$ filtered) was added to the wells. After $15 \mathrm{~min}$, fluorescence was analyzed using a Tecan Infinite M1000 Pro (Tecan, Milan, Italy), with an excitation wavelength of $446 \mathrm{~nm}$, an emission wavelength of $490 \mathrm{~nm}$, and a bandwidth of $20 \mathrm{~nm}$. Each condition was repeated twice in triplicate. Average and standard deviations were calculated and plotted with Excel.

\subsection{ATR FT-IR Spectroscopy}

Hydrogel samples (50 $\mathrm{mM}$ ) were prepared as described above for compounds 1-3, and, after $1 \mathrm{~h}$ of self-assembly, they were placed atop a small piece of Silicon wafer and dried in vacuo overnight. IR spectra were then acquired on an Affinity-1S (Shimadzu, Milan, Italy), diamond, $4 \mathrm{~cm}^{-1}$ resolution, 240 scans).

\subsection{Biocatalysis}

Samples were prepared as described above, and $98 \mu \mathrm{L}$ were immediately put in wells of Greiner 96 U Bottom Transparent Polystyrene. Compounds 1-3 were tested at $1 \mathrm{mM}$, as well as at higher concentrations. In particular, compound 1 was tested at 25 and $50 \mathrm{mM}$. Hydrogels of 2 were tested at $50 \mathrm{mM}$, while hydrogels of 3 could not be tested at $50 \mathrm{mM}$ due to scattering; hence, they were probed at $25 \mathrm{mM}$. After $4 \mathrm{~h}, 2 \mu \mathrm{L}$ of a solution of pNPA [24] (10 $\mathrm{mM}$ in $\mathrm{MeOH}$ ) was added to the wells, unless otherwise stated (i.e., for more diluted conditions, pNPA concentration was lowered accordingly). Absorbance at $405 \mathrm{~nm}$ was monitored over $1 \mathrm{~h}$ on a Tecan Infinite M1000 Pro (Tecan, Milan, Italy). Each condition was repeated twice in triplicate. $\mathrm{K}_{\mathrm{obs}}$ was calculated as previously described [24].

\section{Conclusions}

$\mathrm{N}$-acetylation and/or C-amidation were shown to affect the self-assembly ability and, to a minor extent, the biocatalytic performance of the heterochiral His-Phe-Phe tripeptide [24]. All three compounds self-organized into nanofibrils, although the $\mathrm{N}$ - 
acetylated analogue $\mathbf{1}$ did not gel at all, and the $\mathrm{N}$-acetylated and $\mathrm{C}$-amidated $\mathbf{3}$ formed irreversible hydrogels. We infer that the presence of fewer hydrogen-bonding donor groups in $\mathbf{1}$ relative to the other compounds negatively affected its ability to interact with water to gel. Furthermore, compounds $\mathbf{2}$ and $\mathbf{3}$ displayed an mgc corresponding to $25 \mathrm{mM}$, in contrast with $50 \mathrm{mM}$ for the parent compound, suggesting that terminal modification increased hydrophobicity and favored hydrogelation.

In particular, $C$-amidated 2 was the only compound of the set to maintain the ability to form thermoreversible hydrogels, with an improvement in catalytic performance. These data confirmed that the presence of a free carboxylic acid at the $C$-terminus did not significantly assist in the catalysis performed by this tripeptide sequence. As an additional value, recent reports described a positive effect of $C$-amidation on the stability and biological performance of short heterochiral peptides [36]. Future studies will focus on other strategies to enhance the catalytic activity of the His-Phe-Phe sequence, for instance, through co-assembly with other peptides bearing different amino acids, such as Ser or Arg, which could mimic the catalytic triad found in hydrolases, or through peptide sequence extension to include the same residues. For instance, addition of Arg units at the termini of short self-assembling peptides was shown to reduce hierarchical association of fibrils and improve gelation kinetics [37].

Supplementary Materials: The following are available online. ${ }^{1} \mathrm{H}$ - and ${ }^{13} \mathrm{C}-\mathrm{NMR}$ spectra, ESI-MS spectra, HPLC traces, and biocatalytic data of compounds 1-3.

Author Contributions: Conceptualization, S.M.; investigation, M.K., A.M.G., and S.V. All authors have read and agreed to the published version of the manuscript.

Funding: The authors acknowledge the Ramón Areces Foundation for supporting A.M.G. with a research fellowship.

Data Availability Statement: Data is contained within the article or Supplementary Material.

Acknowledgments: The authors acknowledge M. Bisiacchi and P. Bertoncin for their kind technical assistance.

Conflicts of Interest: The authors declare no conflict of interest.

Sample Availability: Samples of the compounds 1-3 are available from the authors.

\section{References}

1. Choi, J.-M.; Han, S.-S.; Kim, H.-S. Industrial applications of enzyme biocatalysis: Current status and future aspects. Biotechnol. Adv. 2015, 33, 1443-1454. [CrossRef] [PubMed]

2. Chen, Z.; Wang, Z.; Ren, J.; Qu, X. Enzyme Mimicry for Combating Bacteria and Biofilms. Acc. Chem. Res. 2018, 51, 789-799. [CrossRef] [PubMed]

3. Fulda, S. Smac Mimetics to Therapeutically Target IAP Proteins in Cancer. Int. Rev. Cell Mol. Biol. 2017, 330, 157-169. [PubMed]

4. Busto, E.; Gotor-Fernández, V.; Gotor, V. Hydrolases: Catalytically promiscuous enzymes for non-conventional reactions in organic synthesis. Chem. Soc. Rev. 2010, 39, 4504-4523. [CrossRef] [PubMed]

5. Nothling, M.D.; Xiao, Z.; Bhaskaran, A.; Blyth, M.T.; Bennett, C.W.; Coote, M.L.; Connal, L.A. Synthetic Catalysts Inspired by Hydrolytic Enzymes. ACS Catal. 2019, 9, 168-187. [CrossRef]

6. Palocci, C.; Chronopoulou, L.; Venditti, I.; Cernia, E.; Diociaiuti, M.; Fratoddi, I.; Russo, M.V. Lipolytic Enzymes with Improved Activity and Selectivity upon Adsorption on Polymeric Nanoparticles. Biomacromolecules 2007, 8, 3047-3053. [CrossRef]

7. Lu, Y.; Lv, Q.; Liu, B.; Liua, J. Immobilized Candida antarctica lipase B catalyzed synthesis of biodegradable polymers for biomedical applications. Biomater. Sci. 2019, 7, 4963-4983. [CrossRef]

8. Szkolar, L.; Guilbaud, J.-B.; Miller, A.F.; Gough, J.E.; Saiani, A. Enzymatically triggered peptide hydrogels for 3D cell encapsulation and culture. J. Pept. Sci. 2014, 20, 578-584. [CrossRef]

9. Rowley, A.T.; Nagalla, R.R.; Wang, S.; Liu, W.F. Extracellular Matrix-Based Strategies for Immunomodulatory Biomaterials Engineering. Adv. Healthc. Mater. 2019, 8, e1801578. [CrossRef]

10. Su, L.; Li, Y.; Liu, Y.; An, Y.; Shi, L. Recent Advances and Future Prospects on Adaptive Biomaterials for Antimicrobial Applications. Macromol. Biosci. 2019, 19, e1900289. [CrossRef]

11. Korendovych, I.V.; Dolan, M.A.; Korendovych, I.V. Catalytic peptide assemblies. Chem. Soc. Rev. 2018, 47, 3621-3639. 
12. Duncan, K.L.; Ulijn, R.V.; WestCHEMDepartment of Pure and Applied Chemistry University of Strathclyde Thomas Graham Building Cathedral Street Glasgow G XL UK. Advanced Science Research Center (ASRC)Hunter College City University of New York St Nicholas Terrace New York NY USA Short Peptides in Minimalistic Biocatalyst Design. Biocatalysis 2015, 1, 67-81. [CrossRef]

13. Stavrakoudis, A.; Makropoulou, S.; Tsikaris, V.; Sakarellos-Daitsiotis, M.; Sakarellos, C.; Demetropoulos, I.N. Computational screening of branched cyclic peptide motifs as potential enzyme mimetics. J. Pept. Sci. 2003, 9, 145-155. [CrossRef] [PubMed]

14. Maeda, Y.; Makhlynets, O.V.; Matsui, H.; Korendovych, I.V. Design of Catalytic Peptides and Proteins Through Rational and Combinatorial Approaches. Annu. Rev. Biomed. Eng. 2016, 18, 311-328. [CrossRef] [PubMed]

15. Singh, N.; Kumar, M.; Miravet, J.F.; Ulijn, R.V.; Escuder, B. Peptide-Based Molecular Hydrogels as Supramolecular Protein Mimics. Chem. Eur. J. 2017, 23, 981. [CrossRef]

16. Zhang, C.; Xue, X.; Luo, Q.; Li, Y.; Yang, K.; Zhuang, X.; Jiang, Y.; Zhang, J.; Liu, J.; Zou, G.; et al. Self-Assembled Peptide Nanofibers Designed as Biological Enzymes for Catalyzing Ester Hydrolysis. ACS Nano 2014, 8, 11715-11723. [CrossRef]

17. Singh, N.; Conte, M.P.; Ulijn, R.V.; Miravet, J.F.; Escuder, B. Insight into the esterase like activity demonstrated by an imidazole appended self-assembling hydrogelator. Chem. Commun. 2015, 51, 13213-13216. [CrossRef]

18. Gagni, P.; Romanato, A.; Bergamaschi, G.; Bettotti, P.; Vanna, R.; Piotto, C.; Morasso, C.F.; Chiari, M.; Cretich, M.; Gori, A. A self-assembling peptide hydrogel for ultrarapid 3D bioassays. Nanoscale Adv. 2019, 1, 490. [CrossRef]

19. Akagawa, K.; Kudo, K. Solvolysis of Formylphenyl Esters by a Bifunctional Peptide Catalyst. Chem. Lett. 2016, 45, 300. [CrossRef]

20. Carlomagno, T.; Cringoli, M.C.; Kralj, S.; Kurbasic, M.; Fornasiero, P.; Pengo, P.; Marchesan, S. Biocatalysis of D,L-Peptide Nanofibrillar Hydrogel. Molecules 2020, 25, 2995. [CrossRef]

21. Song, R.; Wu, X.; Xue, B.; Yang, Y.; Huang, W.; Zeng, G.; Wang, J.; Li, W.; Cao, Y.; Wang, W.; et al. Principles Governing Catalytic Activity of Self-Assembled Short Peptides. J. Am. Chem. Soc. 2019, 141, 223. [CrossRef] [PubMed]

22. Zhao, Y.; Lei, B.; Wang, M.; Wu, S.; Qi, W.; Su, R.; He, Z. A supramolecular approach to construct a hydrolase mimic with photo-switchable catalytic activity. J. Mater. Chem. B 2018, 6, 2444. [CrossRef] [PubMed]

23. Yang, X.; Wang, Y.; Qi, W.; Su, R.; He, Z. Bioorganometallic ferrocene-tripeptide nanoemulsions. Nanoscale 2017, 9, 15323. [CrossRef] [PubMed]

24. Garcia, A.M.; Kurbasic, M.; Kralj, S.; Melchionna, M.; Marchesan, S. A biocatalytic and thermoreversible hydrogel from a histidine-containing tripeptide. Chem. Commun. 2017, 53, 8110. [CrossRef] [PubMed]

25. Kleinsmann, A.J.; Nachtsheim, B.J. A minimalistic hydrolase based on co-assembled cyclic dipeptides. Org. Biomol. Chem. 2020, 18, 102. [CrossRef] [PubMed]

26. Rufo, C.M.; Moroz, Y.S.; Moroz, O.V.; Stohr, J.; Smith, T.A.; Hu, X.; DeGrado, W.F.; Korendovych, I.V. Short peptides self-assemble to produce catalytic amyloids. Nat. Chem. 2014, 6, 303. [CrossRef]

27. Heier, J.L.; Mikolajczak, D.J.; Böttcher, C.; Koksch, B. Substrate specificity of an actively assembling amyloid catalyst. Pept. Sci. 2017, 108, e23003. [CrossRef]

28. Ting, Y.-H.; Chen, H.-J.; Cheng, W.-J.; Horng, J.-C. Zinc(II)-Histidine Induced Collagen Peptide Assemblies: Morphology Modulation and Hydrolytic Catalysis Evaluation. Biomacromolecules 2018, 19, 2629. [CrossRef]

29. Makam, P.; Yamijala, S.S.R.K.C.; Tao, K.; Shimon, L.J.W.; Eisenberg, D.S.; Sawaya, M.R.; Wong, B.M.; Gazit, E. Non-proteinaceous hydrolase comprised of a phenylalanine metallo-supramolecular amyloid-like structure. Nat. Catal. 2019, 2, 977. [CrossRef]

30. Gayen, K.; Basu, K.; Bairagi, D.; Castelletto, V.; Hamley, I.; Banerjee, A. An amino acid based metallo-hydrogel that acts like an esterase. ACS Appl. Bio Mater. 2018, 1, 1717. [CrossRef]

31. Li, X.; Li, J.; Hao, S.; Han, A.; Yang, Y.; Luo, X.; Fang, G.; Liu, J.; Wang, S. Enzyme mimics based on self-assembled peptides for di(2-ethylhexyl)phthalate degradation. J. Mater. Chem. B 2020, 8, 9601. [CrossRef] [PubMed]

32. Li, Y.; Zhao, Y.; Hatfield, S.; Wan, R.; Zhu, Q.; Li, X.; McMills, M.; Ma, Y.; Li, J.; Brown, K.L.; et al. Dipeptide seryl-histidine and related oligopeptides cleave DNA, protein, and a carboxyl ester. Bioorg. Med. Chem. 2000, 8, 2675. [CrossRef]

33. Gorlero, M.; Wieczorek, R.; Adamala, K.; Giorgi, A.; Schininà, M.E.; Stano, P.; Luisi, P.L. Ser-His catalyses the formation of peptides and PNAs. FEBS Lett. 2009, 583, 153. [CrossRef] [PubMed]

34. Huang, Z.; Guan, S.; Wang, Y.; Shi, G.; Cao, L.; Gao, Y.; Dong, Z.; Xu, J.; Luo, Q.; Liu, J. Self-assembly of amphiphilic peptides into bio-functionalized nanotubes: A novel hydrolase model. J. Mater. Chem. B 2013, 1, 2297. [CrossRef] [PubMed]

35. Maeda, Y.; Javid, N.; Duncan, K.; Birchall, L.; Gibson, K.F.; Cannon, D.; Kanetsuki, Y.; Knapp, C.; Tuttle, T.; Ulijn, R.V.; et al. Discovery of Catalytic Phages by Biocatalytic Self-Assembly. J. Am. Chem. Soc. 2014, 136, 15893. [CrossRef] [PubMed]

36. Gulseren, G.; Khalily, M.A.; Tekinay, A.B.; Guler, M.O. Catalytic supramolecular self-assembled peptide nanostructures for ester hydrolysis. J. Mater. Chem. B 2016, 4, 4605. [CrossRef]

37. Cringoli, M.C.; Romano, C.; Parisi, E.; Waddington, L.J.; Melchionna, M.; Semeraro, S.; De Zorzi, R.; Grönholm, M.; Marchesan, S. Bioadhesive supramolecular hydrogel from unprotected, short D,L-peptides with Phe-Phe and Leu-Asp-Val motifs. Chem. Commun. 2020, 56, 3015. [CrossRef]

38. Marchesan, S.; Vargiu, A.V.; Styan, K.E. The Phe-Phe Motif for Peptide Self-Assembly in Nanomedicine. Molecules 2015, $20,19775$. [CrossRef]

39. Anderson, J.; Byrne, T.; Woelfel, K.J.; Meany, J.E.; Spyridis, G.T.; Pocker, Y. The Hydrolysis of p-Nitrophenyl Acetate: A Versatile Reaction To Study Enzyme Kinetics. J. Chem. Educ. 1994, 71, 715. [CrossRef] 
40. Delort, E.; Nguyen-Trung, N.-Q.; Darbre, T.; Reymond, J.-L. Synthesis and Activity of Histidine-Containing Catalytic Peptide Dendrimers. J. Org. Chem. 2006, 71, 4468. [CrossRef]

41. Cederholm, M.T.; Stuckey, J.A.; Doscher, M.S.; Lee, L. Histidine pKa shifts accompanying the inactivating Asp121-Asn substitution in a semisynthetic bovine pancreatic ribonuclease. Proc. Natl. Acad. Sci. USA 1991, 88, 8116. [CrossRef] [PubMed]

42. Edgcomb, S.; Murphy, K. Variability in the pKa of histidine side-chains correlates with burial within proteins. Proteins 2002, 49, 1. [CrossRef] [PubMed]

43. Harris, T.K.; Turner, G.J. Structural Basis of Perturbed pKa Values of Catalytic Groups in Enzyme Active Sites. IUBMB Life 2002, 53, 85. [CrossRef] [PubMed]

44. Tang, C.; Smith, A.M.; Collins, R.F.; Ulijn, R.V.; Saiani, A. Fmoc-diphenylalanine self-assembly mechanism induces apparent pKa shifts. Langmuir 2009, 25, 9447. [CrossRef] [PubMed]

45. Zhang, C.; Shafi, R.; Lampel, A.; MacPherson, D.; Pappas, C.G.; Narang, V.; Wang, T.; Maldarelli, C.; Ulijn, R.V. Switchable Hydrolase Based on Reversible Formation of Supramolecular Catalytic Site Using a Self-Assembling Peptide. Angew. Chem. Int. Ed. 2017, 56, 14511. [CrossRef] [PubMed]

46. Ryan, D.M.; Doran, T.M.; Anderson, S.B.; Nilsson, B.L. Effect of C-Terminal Modification on the Self-Assembly and Hydrogelation of Fluorinated Fmoc-Phe Derivatives. Langmuir 2011, 27, 4029. [CrossRef] [PubMed]

47. Iglesias, D.; Melle-Franco, M.; Kurbasic, M.; Melchionna, M.; Abrami, M.; Grassi, M.; Prato, M.; Marchesan, S. Oxidized Nanocarbons-Tripeptide Supramolecular Hydrogels: Shape Matters! ACS Nano 2018, 12, 5530. [CrossRef] [PubMed]

48. Garcia, A.M.; Iglesias, D.; Parisi, E.; Styan, K.E.; Waddington, L.J.; Deganutti, C.; De Zorzi, R.; Grassi, M.; Melchionna, M.; Vargiu, A.V.; et al. Chirality Effects on Peptide Self-Assembly Unraveled from Molecules to Materials. Chem 2018, 4, 1862. [CrossRef]

49. Marchesan, S.; Styan, K.E.; Easton, C.D.; Waddington, L.; Vargiu, A.V. Higher and lower supramolecular orders for the design of self-assembled heterochiral tripeptide hydrogel biomaterials. J. Mater. Chem. B 2015, 3, 8123. [CrossRef]

50. Biancalana, M.; Koide, S. Molecular mechanism of Thioflavin-T binding to amyloid fibrils. Biochim. Biophys. Acta 2010, $1804,1405$. [CrossRef]

51. Wu, C.; Biancalana, M.; Koide, S.; Shea, J.E. Binding modes of thioflavin-T to the single-layer beta-sheet of the peptide selfassembly mimics. J. Mol. Biol. 2009, 394, 627. [CrossRef] [PubMed]

52. Amdursky, N.; Erez, Y.; Huppert, D. Molecular rotors: What lies behind the high sensitivity of the thioflavin-T fluorescent marker. Acc. Chem. Res. 2012, 45, 1548. [CrossRef] [PubMed]

53. $\mathrm{Wu}, \mathrm{C}$; Bowers, M.T.; Shea, J.E. On the origin of the stronger binding of PIB over thioflavin T to protofibrils of the Alzheimer amyloid-beta peptide: A molecular dynamics study. Biophys. J. 2011, 100, 1316. [CrossRef] [PubMed] 